\title{
PESQUISA DE ANTICORPOS PARA SIFILIS E TOXOPLASMOSE EM RECÉM-NASCIDOS EM HOSPITAL DE RIBEIRÃO PRETO, SP, BRASIL *
}

\author{
Sueli Marlene Visentini Barreto * * \\ João Carlos da Costa *** \\ Arthur Lopes Gonçalves ****
} BARRETO, S.M.V. et al. Pesquisa de anticorpos para sífilis e toxoplasmose em recém-nascidos em hospi-
tal de Ribeirão Preto, SP, Brasil. Rev.Saúde públ., S. Paulo, $21: 55-63,1987$.

RESUMO: Foram aplicados testes para pesquisa dos niveis de Ig M (por imunodifusão radial simples) e de anticorpos para sífilis (FTA-ABS-IgG e IgM, VDRL e Wassermann (W) e toxoplasmose (imunofluorescência IgG (IFI-IgG) e IgM (IFI-Ig M) em 408 casos de recém-nascidos (RN) do Hospital das Clínicas da Faculdade de Medicina de Ribeirão Preto da Universidade de São Paulo (Brasil), escolhidos casualmente no período de 01/07 a 09/10/198 1. O fator reumatóide (FR) foi pesquisado para excluir resultados falso-positivos para anticorpos classe IgM. Os soros IFI-IgG positivos, e eventualmente falso-negativos à IFI-I gM para toxoplasmose, foram tratados por cromatografia em gel. Um soro positivo para FR foi tratado com gamaglobulina humana agregada pelo calor antes da pesquisa de anticorpos Ig M. Confrontou-se os soros reagentes para sífilis com dados de prontuários dos respectivos $\mathrm{RN}$ e mães. Foram reagentes a pelo menos um dos testes para sífilis $7,0 \%$ dos RN; o FTA-ABS-IgG foi positivo em 89,3\%, o VDRL em $67,8 \%$ e o W em $60,7 \%$. Um soro foi FTA-ABS-IgM reagente. A co-positividade entre FTA-ABS-IgG e VDRL foi $60,7 \%$; entre FTA-ABS-IgG e W $53,6 \%$ e entre VDRL e W $60 \%$. A confrontação mostrou que em $53,5 \%$ dos RN a sorologia foi positiva ao nascimento, em $3,6 \%$ negativa e em $42,9 \%$ não havia dados. O seguimento clínico-sorológico revelou que 2 RN evoluíram com sinais de lues congênita e outros 2 a suspeita clínica foi descartada pela sorologia de controle; em 21 não havia dados. Foram reagentes à IFI-IgG para toxoplasmose $71,3 \%$ dos RN e $100 \%$ não reagentes à IFI-I gM antes e após a cromatografia. No período estudado não houve diagnóstico clínico de toxoplasmose congênita. Três $R N$ apresentaram valores de IgM aumentados, mas não houve diagnóstico clínico ou laboratorial de lues ou toxoplasmose congênitas nos mesmos. Sugere-se a nivel local introdução do FTA-ABS-IgG para triagem mais abrangente da sífilis congênita.

UNITERMOS: Sífilis congênita, diagnóstico. Toxoplasmose congênita, diagnóstico. Reação de Wasserman. Imunofluorescência. Testes de difusão em gel. IgG, análise. IgM, análise.

\section{INTRODUÇÃO}

As infecções congênitas ainda se encontram entre as principais causas de morbidade e mortalidade no periodo neonatal. Nos países industrializados sua prevalência é estimada entre 0,3 e $5 \%$ dos neonatos, podendo ser acima de $10 \%$ nos paises em desenvolvimento, sendo responsabilizadas por $25 \%$ dos recém-nascidos (RN) com baixo peso para a idade gestacional e $13 \%$ dos casos de retardo mental nos Estados Unidos ${ }^{11}$. Elas apresentam-se desde formas graves, exuberantes, até formas totalmente assintomáticas.

A toxoplasmose congênita é, com freqüência, mal diagnosticada clinicamente, mesmo na forma generalizada da doença, sendo que $70 \%$ dos $\mathrm{RN}$ infectados são assintomáticos ${ }^{1}$ e nesta forma permanecem por anos. Em relação a dados locais, Mauad e $\operatorname{col}^{13}$, no Hospital das Clínicas da Faculdade de Medicina de Ribeirão Preto (HCFMRP - USP), no período de 1978 a 1982 ,encontraram uma incidência de um caso de toxoplasmose - doença para cada 723 nascimentos.

Da mesma forma que a toxoplasmose congênita, a sífilis congênita também pode apresentar-se com sinais clínicos pouco evidentes ou ser completamente assintomática ao nascer, sendo que ambas se destacam entre as infecções congênitas porque seu

* Resumo da tese de doutorado apresentada à Faculdade de Medicina de Ribeirão Preto da USP, 1986, de autoria de S.M.V. Barreto, subordinada ao título "Pesquisa de anticorpos para sífilis e toxoplasmose em recém-nascidos do Hospital das Clínicas da Faculdade de Medicina de Ribeiräo Preto - USP". Subvencionado pelo Conselho Nacional de Desenvolvimento Científico e Tecnológico $(\mathrm{CNPq})$ - Processo $102627 / 80$, e pela CAPES através de convênio realizado com a Faculdade de Medicina de Ribeirão Preto - USP.

* Faculdade de Medicina de Ribeirão Preto da Universidade de São Paulo - 14100 - Ribeirão Preto, SP - Brasil.

** Departamento de Clínica Médica da Faculdade de Medicina de Ribeirão Preto da Universidade de São Paulo - 14100 - Ribeirão Preto, SP - Brasil.

*** Departamento de Puericultura e Pediatria da Faculdade de Medicina de Ribeirão Preto da Universidade de São Paulo - 14100 - Ribeirão Preto, SP - Brasil. 
BARRETO, S.M.V. et al. Pesquisa de anticorpos para sífilis e toxoplasmose em recém-nascidos em hospital de Ribeirão Preto, SP, Brasil. Rev. Saude públ., S. Paulo, $21: 55-63,1987$.

diagnóstico precoce possibilita o respectivo tratamento, que poderá evitar graves repercussões futuras para o paciente.

O diagnóstico etiológico de certeza destas doen. ças, com isolamento do agente, nem sempre é acessível. A alternativa mais viável para tanto é a sorologia específica. $O$ teste de imunofluorescência indireta tem sido empregado e o encontro de IgM específica é compatível com doença em fase ativa. $O$ teste do FTA-ABS-IgM (fluorescent treponemal antibody absorption) para triagem de sifilis congênita é considerado de grande utilidade por alguns autores $^{16,19}$ e questionado por outros ${ }^{10}$. Estes se baseiam na taxa de resultados falso-negativos do teste na vigência de sífilis congênita de aparecimento tardio (35\%). Contudo, como teste confirmatório, particularmente para diferenciar transferência passiva de anticorpos maternos de doença ativa do $\mathrm{RN}$, ele é útil, pois sua taxa de falso-positivo é de apenas $10 \%$.

O teste de imunofluorescência indireta IgM para toxoplasmose no soro do $\mathrm{RN}$ pode apresentar situações de resultado falso-positivo, devido à possibilidade de ocorrência de fendas placentárias e passagem de anticorpos IgM maternos, e também a possibilidade de presença do fator reumatóide no seu soro. Existe também a situação de resultados falso-negativos. O soro do RN poderá conter Ig G específica para toxoplasmose recebida passivamente da mãe e esse IgG pode saturar os locais de ligação do antígeno do toxoplasma e inibir a fixação de IgM específica. Assim, é importante separar IgM de IgG para deteç̧ão de IgM específica.

São baixos os níveis de IgM no sangue do cordão de RN saudáveis, podendo sua quantificação auxiliar na triagem de infe cção congênita, como teste inespecífico, suspeitando-se da sua ocorrência quando os níveis da IgM estiverem aumentados significati. vamente.

A oportunidade de examinar o sangue do cordão para pesquisar eventuais infecções que acometeram o feto, especificamente toxoplasmose e sífilis, reveste-se de importância ímpar, pois o exame desse material poderá evidenciar a existência ou forte suspeita de infecção congênita no concepto. Por vezes esta pode ser inaparente, e neste caso o resul. tado do exame servirá como referência inicial para o seguimento do paciente, permitindo posterior confirmação do diagnóstico naquelas situaçōes em que não se detecta IgM específico e cujos níveis de IgG permanecem estáveis em níveis altos ou se elevem nos primeiros meses de vida; ou permite a exclusão da infecção intraútero da criança, quando os niveis de $\operatorname{IgG}$ específico caem significativamente neste período, evidenciando tratar-se de passagem transplacentária de anticorpos matemos.
Esta pesquisa teve por objetivos:

1) Verificar a incidência de casos suspeitos, laboratorialmente, de toxoplasmose e lues congênita em RN, do HCFMRP - USP, através da determinação, em sangue do cordão, dos seguintes exames:

- níveis de IgM total;

- imunofluorescência indireta para toxoplas. mose (IgM e IgG);

- reações para lues - VDRL e Wassermann qualitativas, FTA-ABS-IgG e IgM.

2) Cotejar os resultados das diferentes reações para sífilis entre si e com a evolução das crianças.

\section{Casuística e Métodos}

Foram incluídos no estudo, ao acaso, $408 \mathrm{re}$ cém-nascidos de ambos os sexos, do HCFMRP-USP, nascidos no período de 1 de julho a 9 de outubro de 1981. Foram utilizadas as seguintes reações para sífilis: a) Reação do VDRL Ortho modificada, da "Ortho Diagnostics", seguindo-se a técnica descrita pelo fabricante; b) Reação de Wassermann (W) qualitativa, método de Wadsworth, Maltaner \& Maltaner, $1931^{22}$ e Almeida, $1956^{2}$ utilizando como reagente antígeno de Kolmer; c) Reação do FTA-ABS. -IgG e IgM - método do "Venereal Disease Re. search Laboratory" de $1968^{21}$ com exceção do uso do Tween 80 . Os conjugados empregados foram da Hyland ou B-D Mérieux com títulos variáveis de $1: 40$ a $1: 80$ para $\operatorname{IgG}$ e $1: 20$ a $1: 30$ para $I g M$, conforme o lote utilizado.

Para as reações de toxoplasmose empregou-se o teste de imunofluorescência indireta IgG e IgM (IFI - IgG e IgM) - método de Camargo, 19647, com modificaçðes introduzidas no Laboratório de Sorologia do HCFMRP. USP (glicerina tamponada na proporção $1: 2$ ). O conjugado foi o mesmo anterior, com títulos $1: 100$ para $I g G$ e $1: 30$ para IgM. $O$ teste de imunofluorescência IgM também foi feito em 291 frações IgM de soros positivos para IgG para pesquisa de eventuais resultados falso-negativos para IgM no soro total. Estas frações foram obtidas por cromatografia do soro em Bio-Gel A.5m (200 - 400 mesh) segundo Pyndiah e col. ${ }^{15}$ 1979 com modificações de Bertoni e col. ${ }^{5} 1983$.

Para controle de resultados falso-positivos dos testes realizou-se a prova de aglutinação do látex em placa para pesquisa do fator reumatóide (FR), com "kit" comercial (laboratórios Wiener e/ou Behring). A diluição usada foi $1: 20$. O material reagente foi tratado com gamablobulina agregada pelo calor, método de Camargo e col. ${ }^{8}$ 1972, com as seguintes modificações para utilização no teste FTA-ABS-IgM: centrifugação da gamaglobulina agregada pelo calor a $1900 \mathrm{~g}$ por $10 \mathrm{~min}$., e adição de $0,5 \mathrm{ml}$. do sobrenadente à mistura do soro (positivo para FTA-ABS.IgM e FR) e. Treponema 
BARRETO, S.M.V. et al. Pesquisa de anticorpos para sífilis e toxoplasmose em recém-nascidos em hospital de Ribeirão Preto, SP, Brasil. R'v. Saúde públ., S. Paulo, 21 : 55-63, 1987.

Reiter nas diluições $1: 2,5,1: 5$ e $1: 10$ que passaram a $1: 5,1: 10$ e $1: 20$.

O nível de IgM no soro total foi pesquisado por imunodifusão radial simples, segundo a técnica de Mancini e col. ${ }^{12}$ 1965, com adaptaçōes introduzidas por Barreto 4,1980 .

\section{RESULTADOS}

A Tabela 1 mostra que houve uma distribuição de valores de $\operatorname{IgM}$ que se concentraram entre 5 a
$15 \mathrm{mg} / \mathrm{dl}$, sendo que apenas 3 crianças estavam acima do limite superior de tolerância determinados em nosso Serviço, que é de $25 \mathrm{mg} / \mathrm{dl}$, e que 16 apresentaram níveis acima de $20 \mathrm{mg} / \mathrm{dl}$, que é o limite mencionado na literatura ${ }^{23}$.

A incidência do fator reumatóide nos soros estudados foi de $0,24 \%$ ( 1 caso), sendo que após sua titulação houve aglutinação visivel macroscopicamente até a diluição $1: 40$.

\section{TABELA 1}

Distribuição dos Valores de Imunoglobulina $M$ Obtidos por Imunodifusão Radial Simples em 408 Soros de Recém-nascidos (Hospital das Clínicas da Fauldade de Medicina de Ribeirão Preto - USP)

\begin{tabular}{cccccccccccc}
\hline $\begin{array}{c}\text { IgM } \\
\mathrm{mg} / \mathrm{d} 1\end{array}$ & $\begin{array}{c}\text { Não } \\
\text { Detectado }\end{array}$ & $<5,18$ & $5,18-10$ & $10-15$ & $15-20$ & $20-25$ & $25-30$ & $30-35$ & $35-40$ & Total \\
\hline $\begin{array}{c}\text { Norómero } \\
\text { de } \\
\text { amostras }\end{array}$ & 2 & 37 & 146 & 157 & 50 & 13 & 2 & 0 & 1 & 408 \\
Percentagem & 0,5 & 9,1 & 35,8 & 38,5 & 12,2 & 3,2 & 0,5 & 0 & 0,2 & 100,0 \\
\hline
\end{tabular}

A Tabela 2 mostra a distribuição da recíproca dos títulos ao teste de IFI-IgG para toxoplasmose: $28,7 \%$ não reagentes e $71,3 \%$ reagentes, sendo que o título mais freqüente foi $1: 255$. Todos os 291 soros Ig $G$ positivos foram fracionados e nenhum deles, na diluição $1: 28$, foi positivo para IgM específica.

TABELA 2

Distribuição dos Resultados da Reação de Imunofluorescência Indireta Ig G para Toxoplasmose (IFIT-Ig G) em 408 Soros de Recém-nascidos (Hospital das Clínicas da Faculdade de Medicina de Ribeirão Preto - USP)

\begin{tabular}{ccccccccc}
\hline \multirow{2}{*}{ IFIT-IgG } & $\begin{array}{c}\text { Não } \\
\text { Reagente }\end{array}$ & 16 & 64 & 256 & 1024 & $\geqslant 4096$ & Total \\
\hline $\begin{array}{c}\text { Número de } \\
\text { amostras }\end{array}$ & 117 & 11 & 31 & 149 & 74 & 26 & 408 \\
$\%$ do total & 28,7 & 2,7 & 7,6 & 36,5 & 18,1 & 6,4 & 100,0 \\
\hline
\end{tabular}

Nas reações para sífilis verificou-se que em 408 $\mathrm{RN}, 1(0,24 \%)$ foi reagente ao FTA-ABS-IgM; $25(6,1 \%)$ ao FTA-ABS-IgG; $19(4,7 \%)$ ao VDRL e $17(4,2 \%)$ ao W. Considerando-se apenas os $28 \mathrm{RN}$ reagentes a pelo menos um dos testes, verificou-se que $3,6 \%$ foram reagentes ao FTA-ABS-Ig M; $89,3 \%$ a FTA-ABS-IgG; $67,9 \%$ ao VDRL e $60,7 \%$ ao W. A Tabela 3 mostra que dos $28 \mathrm{RN}$ reagentes a pelo menos um dos testes, $50 \%$ deles reagiram a três testes, $17,9 \%$ a dois e $32,1 \%$ a só um teste. Considerando-se os 408 soros estudados verifica-se que houve concordância de $97 \%$, porém, para os 28 reagentes, observa-se que a concordância entre FTA-ABS. -IgG e VDRL foi $60,7 \%$; entre FTA-ABS-IgG e W 53,6\% e entre VDRL e W 60\% (Tabela 4). Este fato vem mostrar que as discordâncias de positividade entre estes testes são importantes.
A Tabela 5 compara os dados da pesquisa laboratorial e dos prontuários dos $\mathrm{RN}$ em relação à sífilis e $n$ iveis de IgM no soro. Verifica-se que os niveis de IgM se mantiveram dentro da faixa de normalidade ao nascimento. A hipótese de lues congênita foi levantada no berçário em 3 casos, sendo que um dos suspeitos apresentou periostite aos 45 dias de vida. Outro $\mathrm{RN}$ foi reagente para todas as reações para sí. filis, inclusive ao FTA-ABS-IgM e, somente com 4 meses de idade, ao apresentar periostite, foi feito o diagnóstico clínico de lues congênita.

A Tabela 6, referente à comparação dos resultados da triagem com os dos prontuários mostra que $39,4 \%$ das mães dos RN reagentes apresentavam sorologia positiva, independente de tratamento ou não; $49,9 \%$ não tinham exame sorológico e $10,7 \%$ apresentavam sorologia negativa. Quanto aos dados 
BARRETO, S.M.V. et al. Pesquisa de anticorpos para sífilis e toxoplasmose em recém-nascidos em hospital de Ribeirão Pre to, SP, Brasil. Rev. Saúde públ., S. Paulo, 21 : 55-63, 1987.

dos prontuários dos $\mathrm{RN}, 53,5 \%$ deles apresentavam sorologia positiva (W e/ou VDRL) por ocasião do parto; $3,6 \%$ sorologia negativa e em $42,9 \%$ não havia informações a respeito. A sorologia de controle mostrou negativação em $25 \%$ dos casos e $75 \%$ deles ficaram sem informação.

TABELA 3

Reatividade aos Testes FTA-ABS-IgG, Wassermann e VDRL de 408 Soros de Recém-Nascidos (Hospital das Clínicas da Faculdade de Medicina de Ribeirão Preto - USP)

\begin{tabular}{|c|c|c|c|c|c|}
\hline \multicolumn{3}{|c|}{ Reatividade aos Testes } & \multirow{2}{*}{$\begin{array}{l}\text { No de } \\
\text { soros }\end{array}$} & \multirow{2}{*}{$\begin{array}{c}\% \text { do no total de } \\
\text { reativos }(28) \text { em pelo menos } \\
1 \text { dos } 3 \text { testes }\end{array}$} & \multirow{2}{*}{$\begin{array}{l}\% \text { do no total } \\
\text { examinado }\end{array}$} \\
\hline FTA-ABS-IgG & Wassermann & VDRL & & & \\
\hline+ & + & + & 14 & 50,0 & 3,4 \\
\hline+ & + & - & 1 & 3,6 & 0,3 \\
\hline+ & - & + & 3 & 10,7 & 0,7 \\
\hline- & + & + & 1 & 3,6 & 0,3 \\
\hline+ & - & - & 7 & 25,0 & 1,7 \\
\hline- & + & - & 1 & 3,6 & 0,3 \\
\hline - & - & + & 1 & 3,6 & 0,3 \\
\hline \multicolumn{3}{|c|}{ Total ne reativo a pelo menos 1 dos 3 testes } & 28 & 100,0 & 7,0 \\
\hline \multicolumn{3}{|l|}{ Total no não reativo } & 380 & & 93,0 \\
\hline \multicolumn{3}{|l|}{ Total geral } & 408 & & 100,0 \\
\hline
\end{tabular}

TABELA 4

Avaliação Comparativa da Reatividade de 28 Soros de Recém-nascidos aos Testes Sorológicos para Sífilis (Hospital das Clínicas da Faculdade de Medicina de Ribeirão Preto - USP)

\begin{tabular}{|c|c|c|c|c|c|c|c|c|c|c|c|}
\hline \multirow{4}{*}{$\begin{array}{l}\text { Reatividade } \\
\text { para os testes }\end{array}$} & \multicolumn{11}{|c|}{ Reatividade para os Testes } \\
\hline & \multicolumn{6}{|c|}{ FTA $-A B S-I g G$} & \multicolumn{5}{|c|}{ VDRL } \\
\hline & \multicolumn{2}{|c|}{-} & \multicolumn{2}{|c|}{+} & \multicolumn{2}{|c|}{ Total } & \multicolumn{2}{|c|}{ - } & \multicolumn{2}{|c|}{+} & Total \\
\hline & No & $\%$ & No & $\%$ & No & $\%$ & No & $\%$ & No & $\%$ & No \\
\hline
\end{tabular}

VDRL

$\begin{array}{crrrrrr}- & 1 & 3,6 & 8 & 28,6 & 9 & 32,1 \\ + & 2 & 7,1 & 17 & 60,7 & 19 & 67,9 \\ \text { Total } & 3 & 10,7 & 25 & 89,3 & 28 & 100,0\end{array}$

Wassermann

\begin{tabular}{crrrrrrrrrrrr}
- & 1 & 3,6 & 10 & 35,7 & 11 & 39,3 & 7 & 28,0 & 1 & 4,0 & 8 & 32,0 \\
+ & 2 & 7,1 & 15 & 53,6 & 17 & 60,7 & 2 & 8,0 & 15 & 60,0 & 17 & 68,0 \\
Total & 3 & 10,7 & 25 & 89,3 & 28 & 100,0 & 9 & 36,0 & 16 & 64,0 & 25 & 100,0 \\
\hline
\end{tabular}

$+=$ reativo $\quad-\quad=$ não reativo

\section{DISCUSSÃO}

A literatura médica anterior a década de 80 , relatava que as in fecçōes congênitas eram acompanhadas por niveis aumentados de $\operatorname{IgM}^{14,20}$ no sangue do cordão. Contudo, mais recentemente, vários pesqui. sadores $^{6,17,18}$ começaram a mostrar que nem sem. pre as infecções congênitas se acompanham de aumento dos níveis séricos de IgM no RN. Existe consenso entre esses autores de que os níveis séricos de IgM são elevados nas crianças sintomáticas, po. rém com níveis normais nas assintomáticas. Horwitz ${ }^{9}$ confirma este fato, alem de acrescentar que os níveis de IgM são normais ou mesmo baixos em crianças prematuras com infecção assintomática de inicio retardado. 
BARRETO, S.M.V. et al. Pesquisa de anticorpos para sífilis e toxoplasmose em recém-nascidos em hospital de Ribeirão Preto, SP, Brasil. Rev. Saúde públ., S. Paulo, $21: 55-63,1987$.

TABELA 5

Correlação dos Resultados do Levantamento de Prontuários e dos Dados da Pesquisa em Relação à Sífilis e Níveis de IgM no Soro de Recém-nascidos do Hospital das Clínicas da Faculdade de Medicina de Ribeirāo Preto - USP, 1981

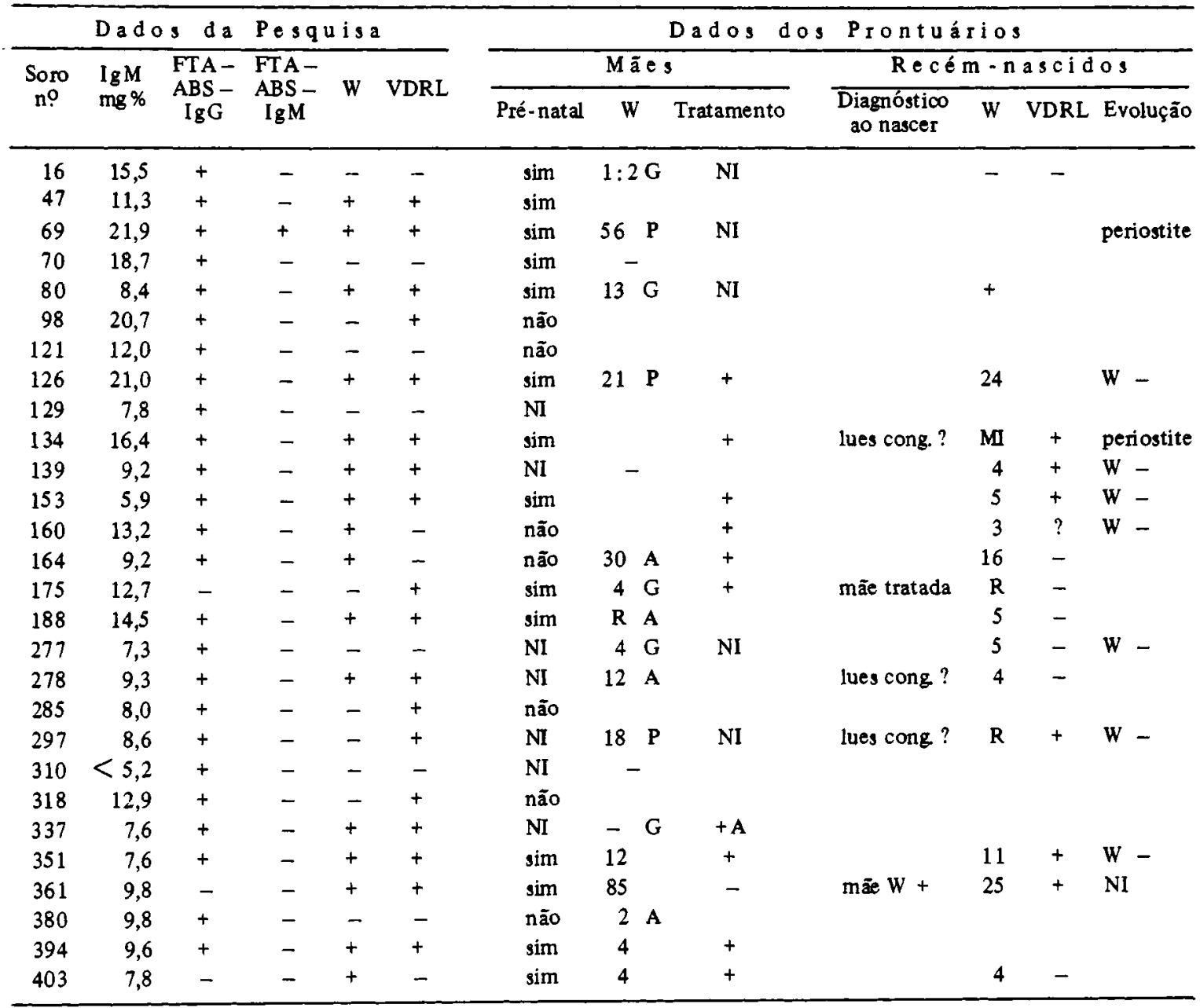

NI $=$ não informado; $G=$ gestação; $P=$ parto; $A=$ antes de engravidar; $R=$ reagente (material insuficiente

$\mathrm{MI}=$ material impróprio; $\mathrm{W}=$ negativação $\mathrm{W}$ para $W$ quantitativo);

Nesta pesquisa apenas três crianças apresentaram $n$ iveis de IgM acima de $25 \mathrm{mg} / \mathrm{dl}$, que é o limite superior de normalidade estabelecido para o nosso meio, tendo como possíveis causas "contaminação" do sangue fetal com passagem de sangue materno para o feto através de fendas placentárias, ou infecção intrauterina ou uma variação da normalidade. Ao se observar os resultados obtidos dessas 3 crianças para as reações de toxoplasmose e lues, verificou-se que foram não reagentes para sífilis e reagentes para toxoplasmose, porém até o título $1: 256$ e somente para IgG. Pode-se interpretar que os níveis séricos elevados de IgM destes 3 RN sejam o reflexo de outros estímulos antigênicos ou mesmo uma variação da normalidade, não se constituindo como indicativo de infecção congênita por lues ou toxoplasmose.
Especialmente em relação à sífilis, os recém-nascidos que apresentaram sorologia positiva mostraram niveis de IgM dentro da faixa de normalidade. Isto sugere a possibilidade de serem crianças tratadas intraútero ou assintomáticas ao nascimento e que posteriormente poderiam ser sintomáticas. Essa última hipótese foi confirmada por ocasião do levantamento dos prontuários das crianças que apresentaram sorologia positiva para lues, pelo menos em 2 casos que tiveram manifestações clínicas da doença, aos 45 dias de vida (soro 134) e com 4 meses (soro 69) e cujos níveis de IgM ao nascer foram respectivamente 16,4 e $21,9 \mathrm{mg} / \mathrm{d} 1$.

Quanto ao fator reumatóide (FR), por ser de ocorrência relativamente al ta em regióes tropicais e 
BARRETO, S.M.V. et al. Pesquisa de anticorpos para sífilis e toxoplasmose em recém-nascidos em hospital de Ribeirão Preto, SP, Brasil. Rev. Saúde públ., S.Paulo, 21 : 55-63, 1987.

\section{TABELA 6}

Correlação Entre 28 Soros de Recém-nascidos, Reagentes após Triagem aos Testes

FTA-ABS e/ou We VDRL, com os Dados de Prontuários das Mães e Destas Crianças,

Relativos a W e/ou VDRL, Tratamento Antiluético e Suspeita de Lues.

(Hospital das Clínicas da Faculdade de Medicina de Ribeirão Preto - USP), 1981

\begin{tabular}{|c|c|c|c|c|c|c|c|c|c|c|c|c|}
\hline \multirow{4}{*}{$\begin{array}{l}\text {-Dados dos } \\
\text { prontuários } \\
\text { maternos }\end{array}$} & \multirow{3}{*}{\multicolumn{2}{|c|}{$\begin{array}{l}\text { RN reagente ao } \\
\text { FTA-ABS } \\
\text { e/ou } \\
\text { We VDRL }\end{array}$}} & \multirow{2}{*}{\multicolumn{6}{|c|}{$\begin{array}{l}\text { Da dos dos Pront } \\
\text { Sorologia na ocasião do parto }\end{array}$}} & dos & $28 R$ & & \\
\hline & & & & & & & & & \multicolumn{4}{|c|}{ Sorologia controle } \\
\hline & & & \multicolumn{2}{|c|}{ positiva } & \multicolumn{2}{|c|}{ negativa } & \multicolumn{2}{|c|}{ sem dados } & \multicolumn{2}{|c|}{ negativa } & \multicolumn{2}{|c|}{ sem dados } \\
\hline & No & $\%$ & No & $\%$ & No & $\%$ & N! & $\%$ & N! & $\%$ & No & $\%$ \\
\hline $\begin{array}{l}\text { Maxes W+ e } \\
\text { tratamento }\end{array}$ & 5 & 17,9 & 4 & 14,2 & 0 & 0 & 1 & 3,6 & 2 & 7,1 & 3 & 10,7 \\
\hline $\begin{array}{l}\text { Maes W+ } \\
\text { não tratadas }\end{array}$ & 1 & 3,6 & 1 & 3,6 & 0 & 0 & 0 & 0 & 0 & 0 & 1 & 3,6 \\
\hline $\begin{array}{l}\text { Máes W+ sem } \\
\text { informaçס̄es } \\
\text { tratamento }\end{array}$ & 5 & 17,9 & 3 & 10,7 & 1 & 3,6 & 1 & 3,6 & 2 & 7,1 & 3 & 10,7 \\
\hline $\begin{array}{l}\text { Mães sem sorologia } \\
\text { porém tratadas }\end{array}$ & 4 & 14,2 & 3 & 10,7 & 0 & 0 & 1 & 3,6 & 2 & 7,1 & 2 & 7,1 \\
\hline $\begin{array}{l}\text { Mães sem W e } \\
\text { não tratadas }\end{array}$ & 10 & 35,7 & 3 & 10,7 & 0 & 0 & 7 & 25,0 & 0 & 0 & 10 & 35,7 \\
\hline Mães W - & 3 & 10,7 & 1 & 3,6 & 0 & 0 & 2 & 7,1 & 1 & 3,6 & 2 & 7,1 \\
\hline Totais & 28 & 100,0 & 15 & 53,5 & 1 & 3,6 & 12 & 42,9 & 7 & 25,0 & 21 & 75,0 \\
\hline
\end{tabular}

ser causa de resultado falso-positivo nas reações de imunofluorescência, sua identificação é imprescindível. A freqüência de positividade do FR entre os RN estudados foi de $0,24 \%$, ou seja, em um único soro. Como esse soro era IgM negativo na reação de IFI para toxoplasmose não houve risco de falso. - positividade. O mesmo não ocorreu na reação FT A. - ABS-IgM, pois um único soro era FR positivo e FTA-ABS-IgM positivo. Então, houve necessidade de se lançar mão de um procedimento que absorvesse o FR. Optou-se pelo tratamento do soro por gamaglobulina humana agregada pelo calor nas diluiçбes $1: 5,1: 10$ e $1: 20$, pois na literatura consultada não havia referências a tal procedimento para as reaçōes de FTA-ABS-IgM. O soro tratado manteve-se positivo nas diluiçóes 1:10 e 1:20 e isso sugere diagnóstico laboratorial de lues congênita. Esse diagnóstico foi confirmado clinicamente após o levantamento do prontuário dessa criança.

Quanto à toxoplasmose, não houve diagnóstico clínico de infecção congênita no período da pesquisa. Todavia, observou-se que $71,3 \%$ dos RN reagiram ao teste de IFI-I gG para toxoplasmose e que todos os 408 soros foram não reagentes ao teste IFI-IgM. A primeira vista, pareceu-nos que a aplicação indiscriminada dos testes nos $408 \mathrm{RN}$ apenas selecionou os portadores de anticorpos IgG anti-toxoplasma, que, se considerados assintomáticos em relação à toxoplasmose congênita, poder-se-ia simplesmente inter- pretá-los como transferidos passivamente das mães. E evidente que essa é a interpretação mais cômoda. Porém, quandase depara com os resultados apresentados vem o dilema do diagnóstico laboratorial em afetados assintomáticos. Quantas das grávidas que transferiram anticorpos aos filhos poderiam ter sido acometidas de toxoplasmose aguda durante esta gestação? A resposta é desconhecida, uma vez que não faz parte da rotina do pré-natal deste hospital a vigilância sorológica ativa desta infecção durante toda a gravidez, o que seria recomendável, principalmente para a grávida ainda não infectada; pois segundo Auerbach e col. ${ }^{3}, 1974$, a viragem sorológica durante a idade fértil é alta, sendo de $32 \%$ em Viena, $19 \%$ em Paris e $40 \%$ em Buenos Aires.

Para a tentativa de diagnóstico precoce desta infecção no $R N$ assintomático, reconsiderou-se a questão dos soros com anticorpos IgG e negativos para IgM no teste de imunofluorescência. Aqui duas possibilidades poderiam ocorrer: o feto ter-se in fectado muito próximo ao parto, ser assintomático, não havendo tempo para a sintese de IgM, ou na vigência de títulos altos de IgG matemo haver competição com I gM do feto e ocasionar um falso-negativo para IgM. Considerando a primeira possibilidade, os RN com quaisquer títulos deveriam ser acompanhados clínica e sorologicamente, pois se houver dados clínicos compativeis, manutenção ou ascensão dos títulos de IgG ou deteç̧ão de IgM específico po. 
BARRETO, S.M.V. et al. Pesquisa de anticorpos para sífilis c toxoplasmose em recém-nascidos em hospital de Ribeirão Preto, SP, Brasil. Rev. Saude públ., S.Paulo, $21: 55-63,1987$.

der-se-ia estabelecer o diagnóstico de toxoplasmose congênita. A segunda possibilidade foi afastada, pois nenhum dos 291 soros com anticorpos IgG antitoxiplasma foi positivo para anticorpos IgM no eluato após a cromat ogra fia em Bio-gel.

O RN assintomático para sífilis cujas provas sorologicas resultam positivas podem estar incubando a doença, ter sido infectado e tratado em útero ou simplesmente possuir anticorpos matemos que fo. ram transferidos passivamente. Na prática médica diária, sobretudo hospitalar, não se pode muitas vezes aguardar modificações da taxa de anticorpos, e muito menos que apareçam manifestações clínicas da doença. Em várias oportunidades, ante o risco de que a mãe não volte às consultas futuras, tem-se medicado o ne on ato.

Nesta triagem o teste FTA-ABS-IgG foi o que apresentou o maior índice de positividade, bem superior ao $\mathrm{W}$ e ao VDRL, tendo esses dois últimos apresentado positividades muito próximas entre si. Como o teste do VDRL é muito simples e rápido e o Wassermann no soro é um método de execução trabalhosa, demorada e que implica no controle de vários parâmetros, poder-se-ia considerar o W como segunda opção como teste para triagem da sífilis. Contudo, o W quantitativo tem sido utilizado em vários serviços, inclusive no nosso, para seguimento de pacientes luéticos, pois o FTA-ABS-IgG é de difícil quantificação, inviabilizando o seguimento a curto e médio prazo dos pacientes e, devido à sua alta sensibilidade, permanece positivo por muitos anos em individuos afetados.

Outro fato que chamou a atenção foi a incidência de $16 \%$ de soros anticomplementares em recém-nascidos na reação de Wassermann qualitativo. Inicialmente, 66 soros foram reagentes com $3 \mathrm{U}$ de complemento e, posteriormente, trabalhandose com 2 e $3 \mathrm{U}$ de complemento para descartar anti. complementaridade, apenas 17 soros se mantiveram como tal. Essa incidência pode ser considerada alta, pelo menos em relação ao encontrado para adultos no mesmo hospital e merece investigação.

Entre os 408 RN da pesquisa, 28 foram reagentes a pelo menos um dos testes para sífilis. Entre eles um $\mathrm{RN}$ apresentou diagnóstico laboratorial de sífilis congênita, ou seja, FTA-ABS-IgM positivo. Nos 27 $\mathrm{RN}$ restantes não se pode concluir sobre sífilis congênita. Isto é devido ao fato de que $O$ início da produção de IgM específico antitreponema pode ser retardado para alguns dias após o parto, fazendo com que um teste negativo no soro do cordão um. bilical não afaste a doença, como ocorre quando a in fecção matema é tardia. Estes RN constituem um grupo de risco cujo seguimento é imprescindivel para que se possa confirmar ou afastar a doença, através da demonstração da persistência da positividade da sorologia além do tempo previsto para o desaparecimento de anticorpos transferidos passivamente.

O levantamento dos prontuários das 28 crianças com sorologia positiva para lues mcstrou que houve ampla variação no aten dimento de rotina em relação ao tratamento matemo e do $\mathrm{RN}$, bem como quanto ao seguimento das crianças, tendo muitas delas faltado aos retornos marcados.

A pesquisa sistemática de anticorpos no sangue do cordão umbilical e o se guimento ambulatorial, clínico e sorológico, destas crianças, seria a forma mais efe tiva de se detectar a doença e tratála precocemente, principalmente as formas inicialmente assintomáticas.

O seguimento clínico e/ou sorológico de alguns $\mathrm{RN}$ mostrou que uma criança apresentou sinais de lues 3.4 meses após o parto, sendo considerado eutrófico ao nascimento, mas que esta triagem o revelou como FTA-ABS-IgM positivo no sangue do cordão. Outro $\mathrm{RN}$ apresentou periostite aos 45 dias de vida, $e$ ao nascimento houve suspeita de lues, sendo filho de mãe sem exame sorológico, porém tratada para sífilis. Em outras duas crianças houve suspeita da doença, todavia a sorologia controle foi negativa (Tabela 5).

A Tabela 6 mostra que, das 28 crianças com pelo menos um teste positivo para sífilis, apenas 15 tiveram esta informação por ocasião do nascimento, uma apresentou W e VDRL negativos e em 12 piontuários não constavam informações a respeito. Também verificou-se que, das 15 crianças com $W$ e/ou VDRL positivos ao nascer, 6 se negativaram nos meses seguintes e uma já era e continuou negativa, totalizan do 7 sorologias negativas, não existindo nos prontuários informações sobre as 21 restantes, ou seja, $75 \%$ delas. Isto, conforme já foi dito, em grande parte se deveu ao não comparecimento dos pais ou responsáveis pelas crianças aos retornos que se marcavam para seguimento das mesmas, além do fato de não se contar, naquela época, com eficiente serviço de vigilância sobre esta doença, o que tem sido aprimorado nos últimos anos.

Quanto ao RN que apresentou reação de FTA. -ABS-IgM negativa e o seguimento clínico revelou periostite aos 45 dias, pode-se interpretá-lo como um falso-negativo, através de duas possibilidades: a mãe ter adquirido sífilis no final da gravidez, o RN ser assintomático e não ter dado tempo para a formação de $\operatorname{IgM}$ específica, ou ter havido reação inibitória de $\mathrm{IgG}$ para $\mathrm{IgM}$.

A extrapolação dos resultados observados pode ser feita para outros períodos, representando com boa fidelidade o que está ocorrendo presentemente no serviço. Com certas reservas, pode também ser extrapolado para serviços similares, de atendimento a pacientes menos favorecidos, devendo-se sugerir reforço nas medidas de triagem desta doença. 
BARRETO, S.M.V. et al. Pesquisa de anticorpos para sífilis e toxoplasmose em recém-nascidos em hospital de Ribeirão Preto, SP, Brasil. Rev.Saúde públ., S.Paulo, 21 : 55-63, 1987.

Diante dos resultados obtidos e considerando que $O$ rastreamento da sífilis matema e infantil neste hospital é feita inicialmente com testes qualitativos para VDRL e W, que apresentam percentuais de positividade menores que o FTA-ABS-IgG, está em andamento proposta de reavaliação da metodologia de triagem da sífilis através dos setores responsáveis pelo controle deste problema e a inclusão deste úl. timo teste, visando aprimorar este rastreamento e detectar praticamente todos os pacientes suspeitos, recomendando-se a sua realização durante o prénatal e por ocasião do parto.

\section{CONCLUSŌES}

- Os níveis séricos de IgM não se revelaram ade. quados para triagem de infecção congênita, tendo sido normais em $98,8 \%$ dos $\mathrm{RN}$, inclusive nos 2 pacientes que apresentaram sifilis congênita, e os 3 casos com IgM maior que $25 \mathrm{mg} / \mathrm{dl}$ não apresentaram patologias in fecciosas na sua evolução.
- No período estudado, não houve diagnóstico laboratorial de toxoplasmose congênita, isto é, não se determinou nenhum $\mathrm{RN}$ com IgM específica no teste de imunofluorescencia. Todavia, $71,3 \%$ dos RN apresentaram anticorpos $I g G$, evidenciando a alta prevalência desta infeç̧ão em sua forma crônica e assintomática nesta população de gestantes.

- A incidência do fator reumatóide, que poderia interferir na reação com IgM positivo, foi de apenas $0,24 \%$.

- Sífilis congenita foi diagnosticada laboratorialmente (FTA-ABS-IgM) em apenas um caso ao nascer. Na triagem laboratorial o teste do FT A-ABS-IgG apresentou o maior índice de positividade $(6,1 \%)$ em relação ao VDRL $(4,7 \%)$ e Wassermann $(4,2 \%)$, qualitativos.

- Com base nos resultados obtidos, propõe-se a in trodução do teste FTA.ABS.IgG para triagem mais abrangente da sifilis congênita e melhoria na profilaxia e tratamento precoce desta doença.

BARRETO, S.M.V. et al. [Research on syphilis and toxoplasmosis antibodies in new-born children in a Ribeirão Preto hospital, S.Paulo, Brazil]. Rev.Saúde públ., S.Paulo, 21 : 55-63, 1987.

ABSTRACT: Tests were performed for the determination of IgM levels (by simple radial immunodiffusion) and antibodies for syphilis (FTA-ABS-IgG and IgM, VDRL and Wassermann (W)) and toxoplasmosis (indirect immunofluorescence IgG (IFI-IgG) and IgM (IFI-IgM)) in 408 new-borns (NB) sera at the University Hospital of the Faculty of Medicine of Ribeirão Preto, USP, selected at random from July 1 to October 9, 1981. Only 3 NB showed greater than normal values of IgM levels in serum, but no clinical or laboratory diagnosis of congenital syphilis or toxoplasmosis was made for them. Two hundred and 91 infants (71.3\%) were IFI-IgG positive for toxoplasmosis and none IFI-IgM, before or after chromatography. No clinical diagnosis of congenital toxoplasmosis was made during the period studied. The rheumatoid factor (RF) was determined in order to exclude false-positive results for antibodies of the IgM class. All possible false-negative sera to IFI-Ig M and IFI-IgG positive for toxoplasmosis were treated by gel chromatography. Only one positive serum for RF was treated with heat-aggregated gamma-globulin before being tested for the presence of IgM antibodies. Sevem percent of the NB (28) were positive to at least one of the tests for syphilis. FTA-ABS-IgG was positive in $89.3 \%$ of them, VDRL in $67.8 \%$ and $\mathrm{W}$ in $60.7 \%$. Only one serum sample was positive for FTA-ABS-IgM. The concordance of positivity between FTA-ABS-IgG and VDRL was $60.7 \%$; $53.6 \%$ between FTA-ABS-IgG and W and $60 \%$ between VDRL and $W$. The syphilis-positive sera were compared with the data in the medical records of the respective NB and their mothers. It was shown that among the $28 \mathrm{NB}$ with positive tests for syphilis only $53.5 \%$ of them were detected at birth, $3.6 \%$ had negative serology and no data were available for $42.9 \%$. Clinical and/or serological follow-up disclosed that $2 \mathrm{NB}$ evolved with signs of congenital syphilis, 2 were suspected to have syphilis, and were treated but control serology ruled out this possibility, and no data were available for 24. A new screening strategy for this disease and the introduction of the FTA-ABS$-I g G$ test for a more extensive selection of congenital syphilis is suggested.

UNITERMS: Syphilis, congenital, diagnosis. Toxoplasmosis, congenital, diagnosis. Wasserman reaction. Fluorescent antibody technic. Gell diffusion test. IgG. analysis. IgM, analysis.

\section{REFERENCIAS BIBLIOGRÁFICAS}

1. ALFORD Jr., C.A.; STAGNO, S. \& REYNOLDS, D.W. Congenital toxoplasmosis: clinical, laboratory and therapeutic considerations, with special reference to subclinical disease. Bull.NY Acad.Med., 50 $160-81,1974$.

2. ALMEIDA, J.O. Isofixation curves as a method of standardizing complement: fixation tests. J.Immu. nol., $76: 259.63,1956$.
3. AVERBACH, S.; AVERBACH, B. \& VILCHES, A.M Prevalência de la infeccion por toxoplasma en personas aparentemente normales de Buenos Aires y alrededores. Bol.As.Pr.med.Arg., 61:460, 1974. Apud AVERBACH, S.; IANOVSKY, J.F. \& SCHMUNIS, G.A. Importância clínica no diagnóstico oportuno da toxoplasmose: diferenciação sorológica das formas agudas e crônicas. São Paulo, s. d. p. 3. 
4. BARRETO, S.M.V. Quantificação de proteinas totais e fraçōes e imunoglobulinas: níveis no soro de recém-nascidos normais do Hospital das Clínicas de Ribeirão Preto. Ribeirão Preto, 1980. [Dissertação de Mestrado - Faculdade de Medicina da USP].

5. BERTONI, L.C.; BALDY, J.L. da S.; PASSOS, J. do N.; OLIVEIRA, J.F.; PEREIRA, J.D.; PASCUAL, J.L.P.; TAKATA, P.K. \& TURINI, T.L. Separação de imunoglobulinas da classe IgM por cromatografia de coluna com Bio-Gel A-5m:valor do seu emprego no diagnóstico da toxoplasmose pelo teste da imunofluorescência indireta. Rev.bras.Patol.clin, 19. 19.22, 1983.

6. BOROBIO, M.V.; NOGALES, M.C. \& PALOMARES, S.C. Value of serological diagnosis in congenital syphilis. Brit.J. vener. Dis, 56:377-80, 1980.

7. CAMARGO, M.E. Improved technique of indirect immunofluorescence for serological diagnosis of toxoplasmosis. Rev.Inst. Med. trop. S. Paulo, $6: 117-8$, 1964.

8. CAMARGO, M.E.; LESER, P.G. \& ROCCA, A. Rheumatoid factors as a cause for false positive IgM antitoxoplasma fluorescent test: a technique for specific results. Rev. Inst.Med.trop.S. Paulo, 14 - 310-3, 1972.

9. HORWITZ, C.A. Laboratory investigation of syphilis. Postgrad. Med., 68:71-9, 1980.

10. KAUFMAN, R.E.; OLANSKY, D.C. \& WIESNER, P.J. The FTA-ABS (IgM) test for neonatal congenital syphilis: a critical review.J.amer. vener. $D i s$. $A$ ss. $1: 79-84,1974$.

11. LECHTIG, A.; DELGADO, H.; IRWIN, M.; KLEIN, R.E.; MARTORELL, R. \& YARBROUGH, C. Intrauterine infection, fetal growth and mental development. J. trop. Pediatr., 25 : 127-38, 1979.

12. MANCINI, G.; CARBONARA, A.O. \& HEREMANS, J.F. Immunochemical quantitation of antigens by single radial immuno-difusion. Immunochemistry, 2: $235-54,1965$.

13. MAUAD, F.; JORGE, S.M.; GROSS, R.; MOREIRA, A.; BORGES, M.; DE OLIVEIRA, D. \& MARTINEZ, A.R. Toxoplasmose e gravidez. Rev. esp. Obst. y Ginecol., 43:282-9, 1984.
14. MILLER, M.J.; SUNSHINE, P.J. \& REMINGTON, J.S. Quantitation of cord serum $\mathrm{Ig} M$ and $\operatorname{IgA}$ as a screening procedure to detect congenital infection: results in 5,006 patients. J.Pediatr., $75: 1287-91$, 1969.

15. PYNDIAH, N. ; KRECH, V.;PRICE, P. \& WILHELM, J. Simplified chromatografic separation of immunoglobulin $M$ from $G$ and its application to toxoplasma indirect immunofluorescence. J.clin. Microbiol., 9 : 170-4, 1979.

16. ROSEN, E.U. \& RICHARDSON, N.J. A reappraisal of the value of the IgM fluorescent treponemal antibody absorption test in the diagnosis of congenital syphilis. J. Pediatr., $87:$ 32-42, 1975.

17. SERRA, G.; BRUSCHETTINI, P.L. ; BONACCI, W.; MAGLIANO, P.; MASTROMATTEO, L. \& CACCIABUE, E. La lue connatale: criteri diagnostici e condotta terapeutica. Minerva Pediatr., 34 : 749-56, 1982.

18. SRINIVASAN, G.; RAMAMURTHY, R.S.; BRARATHI, A.; VOORA, S. \& PILDES, R.S. Congenital syphilis: a diagnostic and therapeutic dilema $P e$. diatr. infect.Dis, 2:436-41, 1983.

19. STEWART Jr., T.W. Interpreting serologic tests for syphilis. Ann. Fam. Physician, $26: 157-62,1982$.

20. STIEHM, E.R.; AMMAN, A.J. \& CHERRY, J.D. Elevated cord macroglobulins in the diagnosis of in trauterine infections. New.Eng.J.Med., $275: 971-7$, 1966.

21. VENEREAL DISEASE RESEARCH LABORATORY Technic for the fluorescent treponemal antibody-absorption (FT A-ABS) test. Hlth. Lab. Sci., 5 : 23-30, 1968.

22. WADSWORTH, A.B.; MALTANER, E. \& MALTANER, F. The quantitative determination of the fixation of complement by immune serum and antigen. J.Immunol., $21: 313-40,1931$.

23. WANG, W.; SPRAGUE, C. \& YOKOYAMA, M. IgM levels in the newborn. Hawaii Med.J., 32:88-91, 1973.

Recebido para publicaçđo em 04/08/1986

Aprovado para publicą̧ão em 12/11/1986 